\title{
Eosinophil Cationic Protein in Human Milk Is Associated with Development of Cow's Milk Allergy and Atopic Eczema in Breast-fed Infants
}

\author{
PAMELA ÖSTERLUND, TANJA SMEDBERG, ARJA HAKULINEN, HANNELE HEIKKILÄ, AND \\ KIRSI-MARJUT JÄRVINEN
}

Helsinki University Central Hospital, Department of Dermatology [P.Ö., T.S., H.H., K.-M.J.], and

Hospital for Children and Adolescents [A.H.], FIN-00029 HUCH, Helsinki, Finland

\begin{abstract}
The precise role of leukocytes and mediators in human milk is still unresolved. Eosinophils are uncommonly detected in human milk and their presence has previously been associated with maternal atopy and development of cow's milk allergy (CMA) in the breast-fed infant. The purpose of this study was to examine the levels of eosinophil cationic protein (ECP) in human milk and to compare the levels with development of allergic diseases in breast-fed infants. Altogether 94 breast-feeding mothers (58 atopic, 36 nonatopic) with their babies were prospectively followed from birth for development of CMA or atopic dermatitis. Colostrum and mature milk samples (at 3 mo of lactation), together with mother's peripheral blood samples, were collected. Milk and blood leukocyte content was evaluated with a light microscope. ECP concentration in human milk was measured by commercial UniCAP method. By the end of a 2-y follow-up, 51 mothers had an infant with CMA, 24 had an infant with atopic
\end{abstract}

ABSTRACT

dermatitis, and 19 had a healthy infant. ECP concentration in milk was under the detection limit $(2 \mu \mathrm{g} / \mathrm{L})$ in all the mothers with a healthy infant, whereas detectable levels were found in $27 \%$ of mothers with a CMA infant and in $42 \%$ of those with a baby with atopic dermatitis. Measurable ECP in milk was detected in $26 \%$ of the atopic and $25 \%$ of the nonatopic mothers. Presence of ECP in human milk is associated with development of CMA and atopic dermatitis in the breast-fed infant, but has no direct association with the maternal atopy. (Pediatr Res 55: 296-301, 2004)
AD, atopic dermatitis
Abbreviations
ECP, eosinophil cationic protein
CMA, cow's milk allergy

Human breast milk provides nutrients and multiple immunologic factors, like secretory IgA, to the breast-fed infant (1). It is known to be an important immunologic support system extending from the mother to her infant during the first months of life. The precise role of leukocytes in human milk is still unknown. In animal studies, milk leukocytes have been shown to pass through the gastrointestinal mucosa of a suckling newborn (2-5). They produce cytokines and mediators, which may be released throughout the gastrointestinal tract (6). In our previous studies, we have found that macrophage is the predominant leukocyte in milk of mothers with a healthy baby, whereas in the mothers with a CMA infant, neutrophils and eosinophils are found in excess (7). We have also shown that

Received October 15, 2002; accepted May 12, 2003.

Correspondence: Pamela Österlund, Ph.D., National Public Health Institute, Department of Microbiology, Mannerheimintie 166, FIN-00300. Helsinki, Finland; e-mail: pamela.osterlund@helsinki.fi

Partially supported (personal grant) by Allergy Research Foundation in Finland (K.M.J.), Finnish Society of Allergology and Immunology (P.Ö.), Research Foundation of Orion Corporation (T.S.), and Nutricia Research Foundation.

DOI: 10.1203/01.PDR.0000106315.00474.6F decreased function of macrophages is likewise associated with development of CMA in breast-fed infants (8), suggesting that defective immunologic support from mother's milk may interfere with normal development of oral tolerance to food proteins.

Eosinophils are mainly tissue-dwelling cells. The bloodtissue ratio of eosinophils has been estimated to be 1:100 (9) Eosinophils are presumably involved in normal immune defense as well as in specific morbid processes including parasitic infections and hypersensitivity reactions $(9,10)$. Eosinophil granules contain cationic proteins, which have been demonstrated in vivo and in vitro to be tissue-destructive (9). Detection of eosinophil-derived granular proteins reflects earlier degranulation of eosinophils and thereby provides evidence of involvement of these cells even when intact cells are not detected (10). Eosinophils are uncommonly detected in human milk and their presence has previously been associated with maternal atopy and development of CMA in infants $(7,11)$.

Although prolonged breast-feeding has been recommended to prevent or delay development of food allergies and atopic eczema in infants (12-16), contradictory reports also exist 
(17-20). There have been several reports on development of severe food allergies already during exclusive breast-feeding $(17,18)$. Furthermore, recent findings about the relation of increased duration of breast-feeding and increased risk of breast-fed infant to develop atopy $(19,20)$ suggest that the protective effect (or a lack thereof) may be caused by individual variations in the levels of immunologic constituents in the mothers' milk. Acknowledging the potentially harmful effects of eosinophils, the purpose of this study was to further investigate the presence of ECP in mother's milk and its association with development of CMA and AD in breast-fed infants.

\section{PATIENTS AND METHODS}

Study protocol. At the beginning of the study, both high-risk and low-risk families were recruited to gain enough babies in each group as follows: One group $(n=77)$ was recruited from the Skin and Allergy Hospital because of infant's high risk for atopy or allergy [atopic or food-allergic sibling(s) or parent(s)] and the other group $(n=17)$ from the Maternity Clinic of Helsinki because of infant's low risk for atopy or allergy (no signs of atopy in first-degree relatives). The participating families were volunteers and they were recruited from June 1995 to September 2001. The mothers gave written informed consent to the study. The Ethical Committee of the Skin and Allergy Hospital of the Helsinki University Central Hospital and the City of Helsinki approved the study protocol.

Study population. The study comprised 94 mothers and their breast-fed infants. The mothers were breast-feeding as long as they wished and their diets were unrestricted. The infants were followed prospectively from delivery for at least $2 \mathrm{y}$ to detect development of $\mathrm{AD}$ or CMA. Only children who were born full-term and had no other chronic diseases were included. Colostrum $(<1 \mathrm{wk})$ and mature milk samples $(3 \mathrm{mo})$ were collected, and mothers' peripheral blood samples were drawn at the same times. The samples from mothers who had had mastitis during the preceding $4 \mathrm{wk}$ were excluded from the analyses.

Elimination diets and diagnostic procedures. Only in the case when a baby showed symptoms of food allergy (AD, urticaria, diarrhea, vomiting, abdominal pain, wheezing) was the mother's diet restricted: foods suspected to cause the symptoms in the infant were eliminated from the mother's and the infant's diet. Most commonly cow's milk or egg were restricted, but frequently also more extensive elimination diets including wheat and some fruits and vegetables had to be applied if symptoms did not ameliorate. After 2-4 wk of elimination diet and symptom-free period, the children were admitted to a clinical cow's milk challenge. All the elimination diets as well as food challenges were performed on the basis of clinical indications, not for research purposes.

The diagnosis of CMA was confirmed by a positive open challenge, which has shown appropriate accuracy in infants (21). The challenge was performed through mothers' milk (18) or directly perorally to the infant. The challenge was started with a drop of cow's milk on the skin or lips. Thereafter, cow's milk was given in increasing doses at half-hour intervals: on d 1 , doses of $1,10,50$, and $100 \mathrm{~mL}$ and on $\mathrm{d} 2$, the normal milk intake appropriate to the infant's age were commenced. The time of the reaction was defined as the time elapsed from the last dose given eliciting the specific symptoms until the end of $1 \mathrm{wk}$ (urticaria, flair of atopic eczema, diarrhea, profuse vomiting, abdominal pain, wheezing). Diagnosis of multiple food allergies was based on at least two positive clinical challenges with foods such as cow's milk, egg, or wheat. The diagnosis of asthma was based on the typical history of symptoms, characteristic clinical findings, and observed bronchial lability according to the generally applied criteria in Finland. Food allergies and asthma were diagnosed by the treating doctor of the infant. $\mathrm{AD}$ was diagnosed by a dermatologist according to the criteria stated by Bos et al. (22).

Skin prick tests and radioallergosorbent test. Skin prick tests were performed on the volar side of the forearm using a commercial cow's milk extract (ALK, Hørsholm, Denmark). Histamine dihydrochloride $10 \mathrm{mg} / \mathrm{mL}$ (ALK) was used as a positive control, and at least a $5-\mathrm{mm}$ diameter of the reaction was taken as an adequate histamine reaction. Reactions were read at $15 \mathrm{~min}$, and at least half $(3 \mathrm{~mm})$ of the size of histamine was taken as a positive reaction. Saline was used as a negative control. Commercial radioallergosorbent test method (Pharmacia Diagnostics, Uppsala, Sweden) was used to measure cow's milk-specific IgE antibodies in patients' sera.

Measurement of human milk ECP. The breasts were washed with warm water before collecting the milk with a manual breast pump. Before the measurement of breast milk ECP, fresh or frozen milk samples $(1 \mathrm{~mL})$ were centrifuged at $18,500 \times g$ for $60 \mathrm{~min}$ at $4^{\circ} \mathrm{C}$, and the translucent supernatants were collected and frozen. After thawing, the samples were diluted 1:2 in ECP Diluent (Pharmacia CAP System, Pharmacia Diagnostics). ECP was measured by UniCAP method (Pharmacia Diagnostics) according to the manufacturer's instructions using a calibrator curve with an extra concentration point of $1 \mu \mathrm{g} / \mathrm{L}$. The results of different runs were equalized, using the comparison of calibrator curves, and are expressed as micrograms per liter.

Light microscopy of breast milk leukocytes. Immediately after the sample collection the milk, 10 to $50 \mathrm{~mL}$ in volume was centrifuged at $400 \times g$ at room temperature for $15 \mathrm{~min}$ to separate the fat layer. Fat and supernatant were removed, and leukocytes were collected and washed $15 \mathrm{~min}$ in RPMI 1640 (Sigma Chemical Co-Aldrich Co Ltd., Irvine, U.K.) containing $5 \%$ fetal bovine serum, antibiotics (penicillin $100 \mathrm{IU} / \mathrm{mL}$ and streptomycin $100 \mu \mathrm{g} / \mathrm{mL}$ ), and $2 \mathrm{mM}$ L-glutamine. After washing three to four times, cells were resuspended in RPMI 1640 media. Subsequently, $1 \times 10^{5}$ leukocytes were attached on each slide by cytospin centrifugation. The object glasses were precoated with Vectabond (Vector Laboratories Inc, Burlingame, CA, U.S.A) to increase the attachment of the human milk leukocytes on the glass. The samples were finally stained with Wright stain (Merck, Darmstadt, Germany) followed by May-Grünwald-Giemsa stain (Oy Reagena Ltd, Kuopio, Finland), and the numbers of macrophages, monocytes, lymphocytes, neutrophils, and eosinophils were counted under a light microscope. The results are expressed as a percentage of the cell type per 100 leukocytes. Samples including erythrocytes or bacteria were discarded. 
Light microscopy of the mothers' peripheral blood leukocytes. Venous blood-EDTA samples were drawn onto slides and stained with May-Grünwald-Giemsa stain. The numbers of different leukocytes were counted under the light microscope. The results are expressed as a percentage of the cell type per 100 leukocytes.

Statistical analysis. Kruskal-Wallis and Mann-Whitney $U$ tests were used to determine the statistical significance of differences between continuous variables. Because of the skewed distributions, logarithmic transformations (ln) were used. $\chi^{2}$ test and Fisher's exact test were applied to determine differences in proportions. The analyses were carried out with NCSS2000 software (Kaysville, UT, U.S.A.).

\section{RESULTS}

Clinical characteristics of study patients. By the end of the $2 \mathrm{y}$ follow-up, mother-infant pairs were divided into three groups according to the clinical status of the infant, and analyses were performed among these groups (see below for details): group 1, 51 mothers [67\% $(n=34)$ with an atopic constitution] had an infant with CMA verified by a challenge; group 2, 24 mothers [ $63 \%(n=15)$ with an atopic constitution] had a baby with $\mathrm{AD}$, and group 3, 19 mothers $[47 \%(n=9)$ with an atopic constitution] had a healthy infant.

Altogether 51 of 57 infants showed a positive cow's milk challenge (group 1). Of them, 14 manifested either urticarial or eczematous skin eruptions, five had gastrointestinal symptoms, and 32 reacted both cutaneously and gastrointestinally. Moredetailed description of clinical characteristics is presented in Tables 1 and 2. Twenty-four infants had itching eczema, distributed in the typical age-related areas, which was diagnosed as $\mathrm{AD}$ by a dermatologist, and treated with topical corticosteroids. Additionally, five of these infants had suspicion of CMA, but the elimination and challenge procedure remained negative, and seven had a positive history of reaction to egg, fish, nut, or tomato but no clinical challenges were performed to confirm the diagnosis. These 24 infants were classified to group 2. The 19 patients without $\mathrm{AD}$ and a negative history of food-related reactions, except one who was suggestive of CMA with gastrointestinal symptoms but whose challenge test remained negative, were classified as healthy (group 3). Their clinical characteristics are presented in Table 1.

In 88 mothers, breast-feeding period occurred totally or partly during pollen season, which is from the beginning of
March until the end of August in Finland. Ten of these mothers had allergic symptoms during the pollen season (seven had hay-fever and three had eczema).

ECP in human milk samples. Milk samples from the first week and at 3 mo of lactation were analyzed separately because of the significant difference in composition of colostrum and mature milk. Colostral samples (d 1-7) were obtained from 15 mothers. The levels of ECP varied within each of the three groups: the median was $2.1 \mu \mathrm{g} / \mathrm{L}$ (range, $<2$ to $92.8 \mu \mathrm{g} / \mathrm{L}$ ) in the CMA group $(n=5), 5.7 \mu \mathrm{g} / \mathrm{L}$ (range, $<2$ to $26.3 \mu \mathrm{g} / \mathrm{L}$ ) in the AD group $(n=4)$, and $6.9 \mu \mathrm{g} / \mathrm{L}$ (range, $<2$ to $55.0 \mu \mathrm{g} / \mathrm{L}$ ) in the healthy group $(n=6)$.

Mature milk samples $(3 \mathrm{mo})$ were examined in 94 mothers. ECP concentration was under the detection limit $(<2 \mu \mathrm{g} / \mathrm{L}$ in 1:2 diluted samples) in all the mothers with a healthy infant, whereas detectable levels were found in $27 \%$ of mothers (14 of 51) with a CMA infant and in $42 \%$ (10 of 24) in those with a baby with AD (Fig. 1). Measurable milk ECP concentrations were significantly detected more often in the mothers with infants with CMA or AD than in those with a healthy infant (CMA versus healthy, $p=0.008$; AD versus healthy, $p=$ 0.001; CMA versus $\mathrm{AD}, p=0.2$; Fisher's exact test).

Amount of milk leukocytes. The proportions of different types of leukocytes in milk of mothers in different study groups are presented in Table 3. Eosinophils were found in the milk of $31 \%$ of mothers with a healthy infant, whereas $37 \%$ of the mothers with an infant with CMA and $18 \%$ of those with an infant with $\mathrm{AD}$ had detectable eosinophils. Thirty-one percent of atopic mothers had eosinophils in their milk compared with $32 \%$ of nonatopic mothers ( $p=0.9, \chi^{2}$ test).

Correlation between milk ECP and leukocyte levels. The detectable levels of ECP in human milk was associated with the higher proportion of neutrophils $(p=0.02)$, but also the higher proportion of eosinophils had a tendency to correlate to detectable ECP levels ( $p=0.08$; Mann-Whitney $U$ test). In 11 of the 24 samples with detectable ECP $(>2 \mu \mathrm{g} / \mathrm{L})$, no eosinophils were detected in the light microscopy slides. Interestingly, three milk samples had clear eosinophilia but no ECP was detected in the milk by the UniCAP method. The lower proportions of human milk macrophages were associated with detectable human milk ECP concentrations ( $p=0.02$; MannWhitney $U$ test).

Correlation between clinical and biologic findings. Table 2 presents the association of clinical characteristics of the CMA infants with the detectable levels of mother's milk ECP. There

Table 1. Number of infants with CMA, AD, or healthy ones having symptoms, and of those whose mothers were on cow's milk elimination diets or had acute atopic symptoms at different times

\begin{tabular}{|c|c|c|c|}
\hline & $\operatorname{CMA}(n=51)$ & $\mathrm{AD}(n=24)$ & Healthy $(n=19)$ \\
\hline Age at appearance of symptoms (median) & $1.5 \mathrm{mo}$ (range, $0.2-11 \mathrm{mo}$ ) & $4.3 \mathrm{mo}$ (range, $0.5-32 \mathrm{mo}$ ) & - \\
\hline Symptomatic during exclusive breast-feeding & 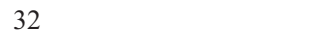 & 5 & 1 \\
\hline \multicolumn{4}{|l|}{ Symptomatic at } \\
\hline 3 mo (mature milk) & 46 & 7 & 1 \\
\hline \multicolumn{4}{|l|}{ Maternal diet at } \\
\hline 1 wk (colostrum) & 0 & 0 & 0 \\
\hline
\end{tabular}


Table 2. Clinical characteristics and mother's milk ECP levels of infants with CMA

\begin{tabular}{|c|c|c|c|c|c|c|}
\hline $\begin{array}{l}\text { Positive cow's milk challenge } \\
(\% \text { of all CMA infants, } n=51)\end{array}$ & $\begin{array}{l}\text { Total amount of } \\
\text { milk eliciting } \\
\text { symptoms* } \\
(\mathrm{mL})\end{array}$ & $\begin{array}{l}\text { Total reaction } \\
\text { time }(\mathrm{h})\end{array}$ & $\begin{array}{c}\text { Positive SPT or } \\
\text { RAST }\end{array}$ & $\begin{array}{l}\text { Multiple food } \\
\text { allergies }\end{array}$ & Asthma & $\begin{array}{l}\text { Positive breast } \\
\text { milk ECP } \uparrow\end{array}$ \\
\hline $\begin{array}{l}\text { Drop of cow's milk on the skin } \\
\qquad(n=13,25 \%)\end{array}$ & & & $n=9(69 \%)$ & $n=10(77 \%)$ & $n=2(15 \%)$ & $n=3(23 \%)$ \\
\hline $\begin{array}{l}\text { Challenge through breast milk } \\
\qquad(n=6,12 \%)\end{array}$ & & & $n=4(67 \%)$ & $n=5(83 \%)$ & $n=3(50 \%)$ & $n=1(17 \%)$ \\
\hline \multicolumn{7}{|l|}{ Peroral challenge } \\
\hline Immediate reaction $(n=10,20 \%)$ & $36(1-360)$ & $1.9(0.25-4)$ & $n=1(10 \%)$ & $n=7(70 \%)$ & $n=3(30 \%)$ & $n=2(20 \%)$ \\
\hline Delayed reaction $(n=20,39 \%)$ & $1081(56-3311)$ & $75.1(5-168)$ & $n=5(25 \%)$ & $n=14(70 \%)$ & $n=4(20 \%)$ & $n=6(30 \%)$ \\
\hline
\end{tabular}

* Median (range). $\dagger \mathrm{ECP}>2 \mu \mathrm{g} / \mathrm{L}$.

Abbreviations: SPT, skin-prick test; RAST, radioallergosorbent test.

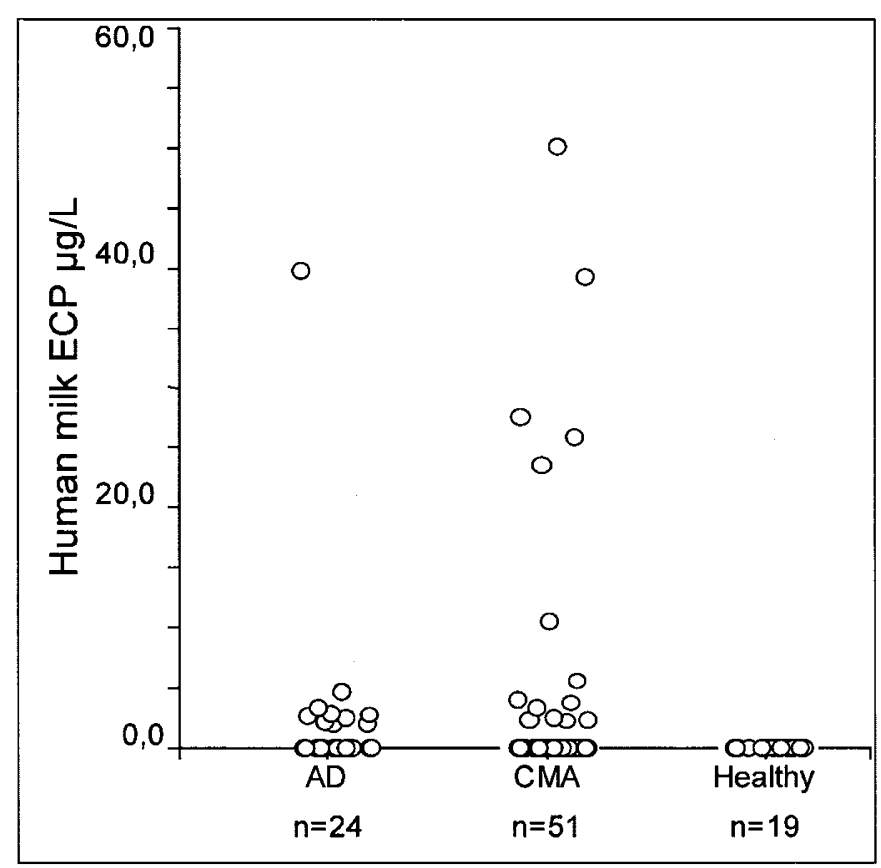

Figure 1. ECP concentrations (micrograms per liter) of mature milk samples (3 mo of lactation) were measured by Pharmacia UniCAP system. Detectable levels were found in the mothers with a breast-fed infant who developed CMA or $\mathrm{AD}$, but not in those with a healthy infant (CMA versus healthy, $p=0.008$; $\mathrm{AD}$ versus healthy, $p=0.001$; CMA versus $\mathrm{AD}, p=0.2$; Fisher's exact test). Detection limit of the assay is $2 \mu \mathrm{g} / \mathrm{L}$.

Table 3. Proportion of different leukocytes in breast milk of mothers with clinically different infants

\begin{tabular}{lcrcc}
\hline & \multicolumn{1}{c}{$\mathrm{AD}$} & \multicolumn{1}{c}{$\mathrm{CMA}$} & \multicolumn{1}{c}{ Healthy } & $p$ value* \\
\hline Macrophages (\%) & $70(18-100)$ & $60(5-98)$ & $67(37-95)$ & 0.08 \\
Monocytes (\%) & $4(0-23)$ & $1(0-22)$ & $5(0-23)$ & 0.07 \\
Neutrophils (\%) & $12(0-80)$ & $13(0-80)$ & $10(0-30)$ & 0.5 \\
Lymphocytes (\%) & $7(0-26)$ & $8(0-88)$ & $12.5(0-41)$ & 0.2 \\
Eosinophils (\%) & $0(0-30)$ & $0(0-33)$ & $0(0-5)$ & 0.25 \\
\hline
\end{tabular}

Values expressed as median (range). * Kruskal-Wallis test.

was no statistical significance in the association of these clinical subgroups of CMA with the mother's milk ECP. Milk ECP concentrations did not differ between the atopic ( $26 \%$ with measurable ECP) and nonatopic (25\% with measurable ECP) mothers $\left(p=0.93 ; \chi^{2}\right.$ test). Each of the mother's milk samples with remarkably high $(>10 \mu \mathrm{g} / \mathrm{L})$ concentrations of ECP was detected during the pollen season. High concentration of milk ECP $(>10 \mu \mathrm{g} / \mathrm{L})$ was detected in two of nine nonatopic mothers with measurable ECP. Among the atopic mothers, the ones who themselves had acute allergic symptoms (hayfever or flare of eczema) at the time of milk sample collection had significantly higher concentrations of ECP in their milk than those who currently showed no allergic symptoms $(p=0.03$; Mann-Whitney $U$ test). Table 4 shows the relation of human milk ECP and the family history of or maternal atopy.

Mothers' peripheral blood leukocytes. The numbers of peripheral blood monocytes, lymphocytes, neutrophils, eosinophils, and basophils were comparable and within normal range in these three study groups of mothers. The proportions of maternal leukocytes did not correlate with their counterparts in milk (data not shown).

\section{DISCUSSION}

As demonstrated in the present prospective study, the presence of ECP in mother's mature milk was associated with development of atopic eczema or CMA in a breast-fed infant during the follow-up of $2 \mathrm{y}$. In this study population $32 \%$ of mothers who had an infant with CMA or AD had detectable levels of ECP in their breast milk, whereas all the mothers with a healthy infant had no ECP in their milk. Furthermore, the detectable level of ECP in mother's milk was not associated with the maternal atopy.

According to the literature, eosinophils are rarely found in human milk (11). Vassella and colleagues (11) have shown that the milk of allergic or atopic mothers contains a relatively high number $(4 \%)$ of eosinophils. It is rather difficult to compare the results of the present study with that of Vassella and colleagues, as no data about the health status of the breast-fed infants were given in their paper (11). In the present study we had relatively high prevalence of CMA and AD in the study population. As a result of recruiting subjects mainly from the allergy unit, the yield of high-risk families was naturally high.

Table 4. Relation of human milk ECP levels to the positive family history of atopy or maternal atopy

\begin{tabular}{lcc}
\hline & $\begin{array}{c}\text { Milk ECP }>2 \mu \mathrm{g} / \mathrm{L} \\
(n=24)\end{array}$ & $\begin{array}{c}\text { Milk ECP }<2 \mu \mathrm{g} / \mathrm{L} \\
(n=70)\end{array}$ \\
\hline Family history of atopy (\%) & $88 \%$ & $80 \%$ \\
Maternal atopy (\%) & $63 \%$ & $61 \%$ \\
\hline
\end{tabular}


During recruitment of low-risk families, we were faced with two disadvantages that resulted in a smaller yield: finding truly nonatopic families with nonatopic first-degree relatives proved to be a more difficult task than expected, and furthermore, the participation rate of such families to a prospective, 2-y study was low.

We have previously shown that in the milk of mothers with a CMA infant, the proportion of macrophages was significantly smaller than in the mothers with infants without CMA (7). Moreover, the mothers with high proportions of neutrophils $(>20 \%)$ or eosinophils $(>1 \%)$ in their milk more often had a CMA infant than the mothers with low proportions of neutrophils or eosinophils (7). In the present study, the proportions of different leukocytes had no relation to the infant's clinical outcome as measured with nonparametric tests of variance. Although the study material is somewhat the same in these two studies, the differences in the results are because of the use of different statistical analyses. In the present study we have shown that $32 \%$ of the mothers having an infant with atopic eczema and CMA during the follow-up had eosinophils or ECP in their milk. These results indicate that in these infants, mother's milk eosinophils or ECP may act as a contributing factor to the pathogenesis of the disease.

ECP is an eosinophil-derived protein that has been demonstrated in vivo and in vitro to be tissue-destructive (10). Eosinophils are essentially tissue-dwelling cells that are seen, for example, in large numbers in the lamina propria of the normal gut (23). In normal, healthy tissue eosinophils are intact, but in diseased tissue they often undergo massive degranulation and release their inflammatory mediators (24). In this study we did not see a correlation, but only a tendency, between human milk eosinophils and the concentration of milk ECP. Even when intact eosinophils were not seen on the slides, detectable ECP in mother's milk provides evidence of previous existence of eosinophilic cells in milk and suggests a possible involvement of eosinophils in immunoinflammatory processes in the breastfed infant (10). Surprisingly, we found a correlation between the amount of human milk neutrophils and the concentration of ECP in breast milk. This kind of correlation in peripheral blood has previously been explained by the suggestion that ECP is actively taken up by blood neutrophils and stored in the granules of these cells $(25,26)$. In three of our samples eosinophils were detected on the slides but there was no measurable ECP in the breast milk of these mothers after ultracentrifugation, a procedure that breaks the cells, releasing all the existing ECP. Undetectable ECP thereby suggests that no or very low levels of ECP were stored in the granules or that the minute amounts of ECP would have been broken down before analysis. Proteolysis of ECP should not, however, have caused the differences in the levels among the groups because all the samples were handled similarly. Alternatively, we suggest that this could partly be explained by the possibility that the eosinophils might be in a different stage of maturation and therefore express inflammatory mediators other than ECP. It is of course also possible that these cells had undergone degranulation in vivo, and therefore intact cells but no ECP can be detected.
The breast milk leukocytes may travel through the gastrointestinal tract of the suckling infant without being destroyed, and this may be related to several protective factors: neutral $\mathrm{pH}$ in the infant's stomach and the neutralizing effect of mother's milk in the gastrointestinal tract $(2,3)$. In the gut of the suckling infant, eosinophils will finally break down by cytolysis during cell death even without any activation process leading to degranulation, and the mediators will be released. Subsequently, the permeability of the gut could be enhanced, and the antigenic load could thereby increase. It has been demonstrated in previous studies that eosinophils and their mediators may have a role in the intestinal inflammation process (27-30). Chung and colleagues (27) have demonstrated elevated levels of eosinophil-derived major basic protein in the intestinal mucosa of infants with cow's milksensitive enteropathy, but they had no evidence about the original source of the major basic protein. Eosinophilic gastroenteritis is characterized by a pronounced intestinal eosinophil accumulation and activation, and the eosinophilic activation is reported to directly reflect to the fecal ECP levels (31). A recent study demonstrated a higher level of fecal ECP in CMA infants with intestinal symptoms than in those with other symptoms or in control subjects (30). In these patients, the authors postulated the allergic inflammation of the intestine was caused by eosinophilic reactions. The possible contributing role of human milk eosinophils or ECP in these inflammatory processes has not been previously investigated. Although the proportion of eosinophils in the total human milk cells is relatively low, a total of $6 \times 10^{6}$ to $7 \times 10^{7}$ eosinophils may be ingested per day by infants born to mothers with high milk eosinophil counts, assuming that several hundred milliliters of milk are being ingested by an exclusively breast-fed baby in $24 \mathrm{~h}$.

In the present study, breast milk ECP was not directly associated with maternal atopy. High concentration of milk ECP $(>10 \mu \mathrm{g} / \mathrm{L})$ was detected in two of nine nonatopic mothers with measurable ECP, indicating that ECP is not purely a phenomenon of atopic constitution of the mother. However, milk ECP levels were higher in the atopic mothers having acute allergic symptoms at the time of milk collection than in the atopic mothers without current symptoms. Consistently, all the samples with considerably high ECP $(>10 \mu \mathrm{g} / \mathrm{L})$ were detected during the pollen season.

\section{CONCLUSIONS}

Taken together, we report a higher level of ECP in human milk to be associated with development of CMA and AD in the breast-fed infant. Furthermore, milk ECP was not directly associated with maternal atopy. The possible role of human milk eosinophils or ECP in contributing to the development of atopic eczema, CMA, or other food allergies in breast-fed babies should be investigated in future studies.

Acknowledgment. The authors thank Pharmacia Diagnostics for UniCAP reagents. 


\section{REFERENCES}

1. Goldman AS, Garza C, Nichols BL, Goldblum RM 1982 Immunologic factors in human milk during the first year of lactation. J Pediatr 100:563-567

2. Paxson CL, Cross CC 1979 Survival of human leukocytes. J Pediatr 94:61-64

3. Mason S 1962 Some aspects of gastric function in the newborn. Arch Dis Child 37:387-391

4. Schnorr KL, Pearson LD 1984 Intestinal absorption of maternal leucocytes by newborn lambs. J Reprod Immunol 6:329-337

5. Jain L, Vidyasagar D, Xanthou M, Ghai V, Shimada S, Blend M 1989 In vivo distribution of human milk leucocytes after ingestion by newborn baboons. Arch Dis Child 64:930-933

6. Järvinen K-M, Laine S, Suomalainen H 2000 Defective tumour necrosis factor-alpha production in mother's milk is related to cow's milk allergy in suckling infants. Clin Exp Allergy 30:637-643

7. Järvinen K-M, Suomalainen H 2002 Leucocytes in human milk and lymphocyte subsets in cow's milk-allergic infants. Pediatr Allergy Immunol 13:243-254

8. Järvinen K-M, Juntunen-Backman K, Suomalainen H 1999 Relation between weak HLA-DR expression on human breast milk macrophages and cow milk allergy (CMA) in suckling infants. Pediatr Res 45:76-81

9. Altman L, Gleich G 1990 Eosinophils. Immunol Allergy Clin North Am 10:263-271

10. Weller PF 1991 The immunobiology of eosinophils. N Engl J Med 324:1110-1118

11. Vassella CC, Hjälle L, Björksten B 1992 Basophils and eosinophils in human milk in relation to maternal allergy. Pediatr Allergy Immunol 3:28-32

12. Zeiger RS, Heller S, Mellon MH, Forsythe AB, O'Connor RD, Hamburger RN, Schatz M 1989 Effect of combined maternal and infant food-allergen avoidance on development of atopy in early infancy: a randomized study. J Allergy Clin Immunol $84: 72-89$

13. Host A, Husby S, Osterballe O 1988 A prospective study of cow's milk allergy in exclusively breast fed infants: incidence, pathogenetic role of early inadvertent exposure to cow's milk formula, and characterization of bovine milk protein in human milk. Acta Paediatr Scand 77:663-670

14. Saarinen UM, Kajosaari M 1995 Breastfeeding as prophylaxis against atopic disease: prospective follow-up study until 17 years old. Lancet 346:1065-1069

15. Lilja G, Dannaeus A, Foucard T, Graff-Lonnevig V, Johansson SGO, Oman H 1989 Effects of maternal diet during late pregnancy and lactation on the development of atopic diseases in infants up to 18 months of age - in vivo results. Clin Exp Allergy 19:473-479

16. Chandra RK, Puri S, Suraiya C, Cheema PS 1986 Influence of maternal food antigen avoidance during pregnancy and lactation on incidence of atopic eczema in infants. Clin Allergy 16:563-569
17. Isolauri E, Tahvanainen A, Peltola T, Arvola T 1999 Breast-feeding of allergic infants. J Pediatr 134:27-32

18. Järvinen K-M, Mäkinen-Kiljunen S, Suomalainen H 1999 Cow's milk challenge via human milk evokes immune responses in suckling infants with cow's milk allergy. J Pediatr 135:506-512

19. Wright AL, Sherill D, Holberg CJ, Halonen M, Martinez FD 1999 Breast-feeding, maternal IgE, and total serum IgE in childhood. J Allergy Clin Immunol 104:589-594

20. Bergmann RL, Diepgen TL, Kuss O, Bergmann KE, Kujat J, Dudenhausen JW, Wahn U, The MAS-Study Group 2002 Breastfeeding duration is a risk factor for atopic eczema. Clin Exp Allergy 32:205-209

21. Isolauri E, Turjanmaa K 1996 Combined skin prick and patch testing enhances identification of food allergy in infants with atopic dermatitis. J Allergy Clin Immunol 97:9-15

22. Bos JD, van Leent EJ, Sillevis Smitt JH 1998 The millennium criteria for the diagnosis of atopic dermatitis. Exp Dermatol 7:132-138

23. Wardlaw JA, Symon FS, Walsh GM 1994 Eosinophil adhesion in allergic inflammation. J Allergy Clin Immunol 94:1163-1171

24. Gleich GJ 1990 The eosinophil and bronchial asthma: current understanding. J Allergy Clin Immunol 85:422-436

25. Venge P, Byström L, Carlson M, Håkansson L, Karawacjzyk M, Peterson C, Sevéus L, Trulson A 1999 Eosinophil cationic protein (ECP): molecular and biological properties and the use of ECP as a marker of eosinophil activation in disease. Clin Exp Allergy 29:1172-1186

26. Byström J, Garcia RC, Håkansson L, Karawajczyk M, Moberg L, Soukka J, Venge P 2002 Eosinophil cationic protein is stored in, but not produced by, peripheral blood neutrophils. Clin Exp Allergy 32:1082-1091

27. Chung HL, Hwang JB, Kwon YD, Park MH, Shin WJ, Park JB 1999 Deposition of eosinophil-granule major basic protein and expression of intercellular adhesion molecule- 1 and vascular cell adhesion molecule- 1 in the mucosa of the small intestine in infants with cow's milk-sensitive enteropathy. J Allergy Clin Immunol 103:1195-1201

28. Majamaa H, Laine S, Miettinen A 1999 Eosinophil protein X and eosinophil cationic protein as indicators of intestinal inflammation in infants with atopic eczema and food allergy. Clin Exp Allergy 29:1502-1506

29. Vandezande LM, Wallaert B, Desreumaux P, Tsicopoulos A, Lamblin C, Tonnel AB, Janin A 1999 Interleukin-5 immunoreactivity and mRNA expression in gut mucosa from patients with food allergy. Clin Exp Allergy 29:652-659

30. Saarinen KM, Sarnesto A, Savilahti E 2002 Markers of inflammation in the feces of infants with cow's milk allergy. Pediatr Allergy Immunol 13:188-194

31. Bischoff SC, Mayer J, Nguyen QT, Stolte M, Manns MP 1999 Immunohistological assessment of intestinal eosinophil activation in patients with eosinophil gastroenteritis and inflammatory bowel disease. Am J Gastroenterol 94:3521-3529 